For years dendritic cells (DCs) have languished on the sidelines of immunology research while T lymphocytes have been given top billing. Now, almost 30 years after discovering them, Ralph Steinman is seeing dendritic cells take center stage.

\title{
Ralph Steinman
}

Born in Canada and now an American citizen who counts ballroom dancing and jogging around Central Park among his interests, Ralph Steinman first became interested in immunology research while studying at Harvard Medical School. He moved to Rockefeller University in 1970 to do postdoctoral research under the mentorship of white blood cell experts Zanvil Cohn and James Hirsch. The two were pioneers in the cell biology of phagocytic cells, and together with Steinman they discovered dendritic cells (DC).

"The tool for eliciting immune responses that was available at the time was something called the Mishell and Dutton culture for making primary antibody responses in suspensions of mouse spleen. We realized that in addition to lymphocytes, you need other cells called accessory cells and it was

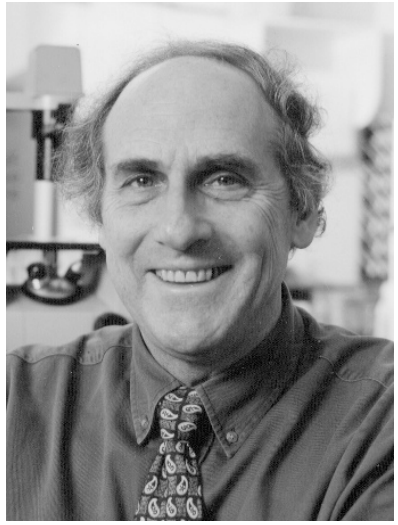

Ralph Steinman cell mediated immunity."

That initial work was reported in 1973 in the Journal of Experimental Medicine ( $\mathrm{J}$. Exp. Med. 137, 1142; 1973). In fact, Steinman became an assistant editor on that journal in 1976 and has held the position of Editor since 1988. He believes that "Publishing is a creative human venture and peer review is one of the many pro bono features of our profession-it is really a terrific educational bonus." Dedication to this journal mirrors his loyalty to Rockefeller University where he has spent his entire scientific research career and is presently the Henry G. Kunkel Professor in cellular physiology and immunology.

It was not until 1979, when Steinman's group learned how to enrich DCs to a high degree of purity, that functional studies on the new cells began, and it took until the early 1990s, when it whilst we were examining these that we spotted the distinctive dendritic cells," says Steinman

The group found that the new cells expressed extremely high levels of major histocompatibility (MHC) complex products - required for antigen presentation to T lymphocytes-and proceeded to test the functionality of these products via a mixed lymphocyte reaction. The DCs were unusually potent. "I'll never forget when we saw the first data coming out of the scintillation counter where we'd measured DNA synthesis by radioactive thymidine incorporation," remembers Steinman. "We knew we were adding very tiny numbers of DC to initiate this mixed leukocyte reaction, yet the proliferation we were observing was just enormous. And that's when the idea arose that these are specialized initiators of $\mathrm{T}$ - from non-self. "If you think of the condition of influenza in the lung, then the DC must first capture and process the virus appropriately so that the $\mathrm{T}$ cell can recognize it..." explains Steinman, "...but it is also capturing self cells that occur naturally in the airway, so how does it avoid inducing immunity to all these particles and how does it focus on the pathogen?"

Using an influenza peptide as a model antigen, Steinman's group compared immature with mature DCs as immunogens for the purposes of cancer immunotherapy. "Instead of getting no response at all with immature cells, which was our hypothesis, we observed the induction of 'regulatory cells' that can suppress immune reactivity. The hypothesis is that the DCs present in our body in steady state are inducing regulatory cells to whatever they capture from the airways, intestine etc."

DCs are one of the sets of cells known to be infected by HIV, and Steinman's group at Rockefeller believes that the virus may be exploiting the tolerizing role of immature DCs, which are known to possess receptors for HIV (i.e. CD4 and CCR5), to enable it to thrive in the body. "If the normal function of immature DCs is to induce tolerance, then HIV may have figured this out as a way to suppress the immune response to itself and that's an ominous part of HIV infection." Steinman's team is also collaborating on research to examine the role that a new receptor called DC-Sign plays in DC-mediated HIV infection.

Thus, decades after discovering DCs, Steinman is inspired by how much work there still is to do, such as understanding how they endocytose material and generate peptides for major histocompatibility complex 1 , why they are so potent at stimulating $\mathrm{T}$ cells, and how they migrate to the lymphoid tissue. "The field is only just beginning," he says.

Karen Birmingham, London 